\title{
Dengue in pregnancy, maternal and fetal outcome: a case series managed at a Zonal Hospital
}

\author{
Tina Singh ${ }^{1 *}$, S. M. Singh², M. M. Paprikar ${ }^{2}$
}

\begin{abstract}
${ }^{1}$ Department of Obstetrics and Gynecology, INHS Asvini and Institute of Naval Medicine, Mumbai, Maharashtra, India

${ }^{2}$ Department of Obstetrics and Gynecology, INHS Kalyani, Visakhapatnam, Andhra Pradesh, India
\end{abstract}

Received: 23 February 2020

Revised: 10 April 2020

Accepted: 15 April 2020

\section{*Correspondence:}

Dr. Tina Singh,

E-mail: afmctina@gmail.com

Copyright: ( ) the author(s), publisher and licensee Medip Academy. This is an open-access article distributed under the terms of the Creative Commons Attribution Non-Commercial License, which permits unrestricted non-commercial use, distribution, and reproduction in any medium, provided the original work is properly cited.

\section{ABSTRACT}

Background: Dengue is a vector borne disease with various grades of severity. Pregnancy is a high-risk group and is prone for complications of dengue haemorrhagic fever. The aim of this study was to evaluate the clinical profile of pregnant patients with dengue and to assess the maternal and fetal outcomes of dengue in pregnancy.

Methods: All pregnant patients reporting to the hospital with fever and serologically confirmed dengue infection were included in the study. Clinical and laboratory data of patients were collected. The cases were followed up till their delivery to monitor the effect of dengue. An account of the mode of delivery in these patients was made. The neonates were evaluated and followed up till 6 weeks of life.

Results: A total $100 \%$ patients reported with fever and serologically confirmed dengue infection. $15 \%$ had severe thrombocytopenia requiring platelet transfusion. 31\% required ICU care and 15\% needed mechanical respiratory support due to severe complications of dengue. NICU admission rate was $30 \%$ but there was no major neonatal complication or vertical transmission noted. A high index of suspicion should be maintained by the clinician with an aim to identify infection early, start supportive treatment and evaluate for complications. In-patient care should be provided for feto-maternal monitoring.

Conclusions: The progression of dengue infection in pregnancy was rapid leading to major complications. Close materno-fetal monitoring and timely obstetric care are essential to ensure a favorable pregnancy outcome

Keywords: Dengue, Dengue hemorrhagic fever, Pregnancy, Thrombocytopenia

\section{INTRODUCTION}

Dengue is one of the vectors borne viral diseases prevalent in the South Asian and South-east Asian regions of the world. ${ }^{1}$ India too has a significant socioeconomic and disease burden as far as dengue is concerned. World Health Organisation defines dengue fever as an acute febrile illness with two/more of the following signs and symptoms: intense headache, retroorbital pain, myalgia, arthralgia, rash, leukopenia and haemorrhagic manifestations.
Clinically dengue has various grades of severity ranging from mild grade self-limiting fever to thrombocytopenia and increased vascular permeability. Evidence of plasma leaking can manifest as elevated haematocrit $>20 \%$ of mean at that age, presence of pleural effusion, ascites or hypoproteinaemia. ${ }^{2}$ Pregnancy is associated with various physiological changes in the body. Moreover, dengue infection during this period poses a risk not only to the mother but also increases fetal complications such as Intrauterine Foetal Demise, low birthweight and prematurity. ${ }^{3}$ In pregnancy, dengue increases the risk of 
hemorrhage for not only the lady but also for the neonate. Vertical transmission to the neonate has been noted. ${ }^{4}$ Though there are limited studies on the effect of dengue on pregnancy, complications such as pre-term births, low birth-weight, pre-eclampsia, high chances of caesarean sections are known. ${ }^{5}$

According to the National guidelines for dengue management released by Government of India, pregnancy is listed as the top high-risk group prone to have severe manifestations and complications of dengue fever and dengue haemorrhagic syndrome. ${ }^{6}$ Therefore, they require close monitoring for severe infection and onset of complications. National statistics suggest that every year, in July-November an upsurge in the number of dengue cases is noted, especially in southern and western states of India, mainly, Andhra Pradesh, Chandigarh, Delhi, Goa, Haryana, Gujarat, Karnataka, Kerala, Maharashtra, Puducherry, Tamil Nadu and West Bengal. ${ }^{7}$

This study has been conducted in a zonal level Armed Forces Hospital in Andhra Pradesh, where in the year 2018 in July-October, a total of 809 dengue cases were treated, out of which 137 were wives of serving Armed Forces personnel. Thus, $16.9 \%$ cases out of the total were females. Out of this female dengue patient population, 13 were pregnant, which makes it $9.48 \%$ of the female quotient. In other words, almost one out of every 10 female dengue patients were a pregnant lady.

The aim of this study was to evaluate the clinical profile of pregnant patients with dengue and to assess the maternal and fetal outcomes of dengue in pregnancy.

\section{METHODS}

This study was carried out in an Armed Forces zonal level hospital. The study population were patients of reproductive age group visiting the antenatal OPD with fever. The study period were the months from July to October since a surge in dengue cases were noted in this period. All pregnant patients reporting to the hospital with fever and serologically confirmed dengue infection were included in the study irrespective of the gestational age.

\section{Inclusion criteria}

- Patients of 20-40-year age with viable pregnancy confirmed with ultrasound

- Having fever which is clinically recordable

- Dengue serology, NS1 antigen and/or IgG or IgM positive, by ELISA method

- Patients willing to follow-up after delivery upto 6 weeks.

\section{Exclusion criteria}

- Patients with non-viable pregnancy and fever with negative dengue serology.
Since this was a retrospective observational study, data of 13 pregnant patients with confirmed dengue infection were collected. This included their age, parity, gestational age, detailed history, clinical examination, relevant blood investigations (complete blood counts, serial platelet counts, liver function test, renal function test, coagulation profile). Few patients with dengue haemorrhagic fever had severe complications and were managed in intensive care units. These patients were evaluated further depending on case to case basis. The data obtained was then tabulated in a master chart and analysed.

The cases were followed up till their delivery to monitor the effect of dengue on the natural course of pregnancy in these patients. An account of the mode of delivery in these patients was made. The neonates born were evaluated by being subjected to dengue serology and platelet count laboratory investigations and were followed up till 6 weeks of life.

\section{RESULTS}

In this study, 13 pregnant patients with confirmed dengue infection reporting to OPD within the age group of 19-35 years were included.

Table 1: Gestational age at diagnosis.

\begin{tabular}{|lll|}
\hline $\begin{array}{l}\text { Gestational age } \\
\text { (in weeks) }\end{array}$ & No. of patients & Percentage \\
\hline$<13$ & 2 & $15 \%$ \\
\hline $13-28$ & 4 & $31 \%$ \\
\hline$>28$ & 7 & $54 \%$ \\
\hline Total & 13 & $100 \%$ \\
\hline
\end{tabular}

Out of the 13 cases, authors only had $2(15 \%)$ cases who had dengue in the first trimester, $4(31 \%)$ had the infection in the second trimester, whereas $7(54 \%)$ had dengue in the third trimester.

Table 2: Symptoms on reporting.

\begin{tabular}{|lll|}
\hline Symptoms & No. of patients & Percentage \\
\hline Fever & 13 & $100 \%$ \\
\hline Myalgia & 10 & $77 \%$ \\
\hline Headache & 4 & $31 \%$ \\
\hline Skin rash & 11 & $85 \%$ \\
\hline Petechia & 2 & $15 \%$ \\
\hline Abdominal pain & 1 & $8 \%$ \\
\hline Breathlessness & 3 & $23 \%$ \\
\hline
\end{tabular}

Amongst the pregnant patients with dengue infection, all had fever when they reported to the hospital, with 11 $(85 \%)$ of them having a skin rash and $10(77 \%)$ reporting with myalgia. Other patients had headache, petechiae, breathlessness and abdominal pain.

On evaluation it was found that all these patients had ELISA for NS1 antigen positive. Whereas, 3 patients 
were found to have IgG positive and only one had IgM positive.

Table 3: Serological reporting of dengue.

\begin{tabular}{|ll|}
\hline Serological test & No. of cases \\
\hline NS1 & 13 \\
\hline IgM & 1 \\
\hline IgG & 3 \\
\hline
\end{tabular}

Table 4: Severity of thrombocytopenia.

\begin{tabular}{|lll|}
\hline Platelet count/cubic mm & $\begin{array}{l}\text { No. of } \\
\text { patients }\end{array}$ & Percentage \\
\hline$<50,000$ & 2 & $15 \%$ \\
\hline $50,000-1$ lac & 6 & $46 \%$ \\
\hline $1-1.5$ lac & 4 & $31 \%$ \\
\hline$>1.5$ lac & 1 & $8 \%$ \\
\hline Total & 13 & $100 \%$ \\
\hline
\end{tabular}

The patients were further subjected to platelet count investigation to detect the severity of thrombocytopenia. It was noted that $46 \%$ patients had platelet count between 50,000 to 01 lac, whereas in $31 \%$ it ranged between 1-1.5 lac. In 2 patients the platelets dropped below $50,000 /$ cubic $\mathrm{mm}$. Also, there were features of capillary leakage in these two patients, evident clinically in the form of pleural effusion and ascites in both and thus they were monitored in ICU and were transfused platelets. Fetal monitoring was continued for these patients while they were in the ICU, and there were no features of antepartum hemorrhage noted.

Table 5: Maternal complications.

\begin{tabular}{|lll|}
\hline $\begin{array}{l}\text { Complications of dengue } \\
\text { haemorrhagic fever }\end{array}$ & $\begin{array}{l}\text { No. of } \\
\text { patients }\end{array}$ & Percentage \\
\hline Hypoproteinaemia & 1 & $8 \%$ \\
\hline Ascites & 2 & $15 \%$ \\
\hline Massive pleural effusion & 3 & $23 \%$ \\
\hline
\end{tabular}

Table 6: Effect of severe dengue infection.

\begin{tabular}{|l|l|}
\hline Effect of severe infection & $\begin{array}{l}\text { No. of } \\
\text { patients }\end{array}$ \\
\hline Requirement of ICU care & 4 \\
\hline Need for platelet transfusion & 2 \\
\hline Need for mechanical ventilation (CPAP) & 2 \\
\hline
\end{tabular}

Amongst maternal complications it was observed that 06 patients out of 13 had complications of dengue haemorrhagic fever leading to capillary leakages resulting in pleural effusion in $3(23 \%)$, ascites in $2(15 \%)$ and hypoproteinaemia in $1(8 \%)$. Out of the 3 patients with pleural effusion, two of them had to be given mechanical ventilatory support for a short duration along with supportive therapy till the critical phase of dengue settled down and plasma leakages stopped, resolving pleural effusion and ascites.
Overall, 4 patients required ICU care, two needed ventilatory support and platelet transfusion was given to two patients out of the 13 cases that were managed.

The patients continued to undergo antenatal care and feto-maternal monitoring. $5(38 \%)$ patients had a term vaginal delivery, whereas $6(46 \%)$ had caesarean section. Amongst these term caesareans, 4 were due to fetal indications (severe oligohydramnios, non-reassuring nonstress test, thick Meconium stained liquor with fetal distress) whereas the other 2 were post-caesarean elective sections. One patient had absent diastolic flow in umbilical artery Doppler at 34 weeks gestation with oligohydramnios and underwent preterm caesarean delivery.

Table 7: Outcome of pregnancy.

\begin{tabular}{|lll|}
\hline Mode of delivery & $\begin{array}{l}\text { No. of } \\
\text { patients }\end{array}$ & Percentage \\
\hline Term vaginal & 5 & $38 \%$ \\
\hline Term caesarean section & 6 & $46 \%$ \\
\hline Preterm caesarean section & 1 & $8 \%$ \\
\hline Lost to follow-up & 1 & $8 \%$ \\
\hline Total & 13 & $100 \%$ \\
\hline
\end{tabular}

Pregnancy outcome data of only 12 patients were available since 1 patient was lost to follow-up in the third trimester. Out of the remaining 12 patients, meconium staining of liquor suggesting placental insufficiency was observed in 5 patients $(38 \%)$. Whereas, 1 each had abnormal fetal doppler, severe oligohydramnios and fetal distress each.

Table 8: Foetal complications.

\begin{tabular}{|lll|}
\hline Fetal complication & $\begin{array}{l}\text { No. of } \\
\text { patients }\end{array}$ & Percentage \\
\hline $\begin{array}{l}\text { Absent diastolic flow (34 } \\
\text { weeks POG) }\end{array}$ & 1 & $8 \%$ \\
\hline Meconium stained liquor & 5 & $38 \%$ \\
\hline Fetal distress & 1 & $8 \%$ \\
\hline Severe oligohydramnios & 1 & $8 \%$ \\
\hline
\end{tabular}

Table 9: Neonatal complications.

\begin{tabular}{|lll|}
\hline Neonatal complications & $\begin{array}{l}\text { No. of } \\
\text { patients }\end{array}$ & Percentage \\
\hline Normal & 7 & $54 \%$ \\
\hline NICU admissions & 4 & $30 \%$ \\
\hline Prematurity & 1 & $8 \%$ \\
\hline Lost to follow-up & 1 & $8 \%$ \\
\hline
\end{tabular}

The neonates born to these patients were monitored up to 6 weeks of life. Their serological testing revealed that none of them had dengue infection due to vertical transmission. Also, none had thrombocytopenia or complications due to bleeding manifestations. However, $4(30 \%)$ neonates required NICU care, 1 being premature 
and 3 being found to have low Apgar score at 1 minute. Authors didn't have the data of the neonate of one patient who didn't follow up in the hospital in the third trimester.

\section{DISCUSSION}

During times of dengue outbreaks, any pregnant patient reporting with fever should be evaluated for dengue. A high index of suspicion should be maintained by the clinician with an aim to identify infection early, start supportive treatment and evaluate for complications. Inpatient care should be provided for feto-maternal monitoring, and to de-stress the anxious patient and her relatives, since any infection in pregnancy is a major cause of concern. ${ }^{7}$

In this study, 13 pregnant patients with dengue infection, in the age group of 19-35 years were included. All the patients had presented with fever ranging between 99103 'F, whereas, $85 \%$ had skin rash and $77 \%$ had myalgia (Table 2). Other common symptom on presentation included headache and breathlessness. 54\% of this case were in their final trimester of pregnancy (Table 3). Severe thrombocytopenia with complications were noted in $2(15 \%)$ cases (Table 4$)$. Out of this one patient was transfused 08 random donor platelets (RDP) and the other 6 RDPs. Single donor platelets (SDP) could not be given in view of their high demand and limited availability.

A total 4 of this study patients required ICU care and 2 out of these, had to be given mechanical ventilation in view of acute respiratory distress syndrome and massive pleural effusion. The liver and renal functions of all patients were normal.

Various levels of placental insufficiencies were noted in study patients (Table 8 ). $46 \%$ of study patients had caesarean sections and $38 \%$ had term vaginal delivery, while $8 \%$ had preterm delivery (Table 7). Though 30\% of the neonates required NICU care (Table 8), it was observed that none of these neonates had significant thrombocytopenia and moreover, there was no vertical transmission of dengue in them.

\section{CONCLUSION}

This study highlights on the clinical course of dengue in pregnant patients and its effect on the natural course of pregnancy.

Though the presentation of the infection in pregnancy was not different from that in non-pregnant patient, it is pertinent to mention that the progression of the infection in pregnancy was rapid leading to major complications in significant percentage of patients.

A high clinical suspicion, low threshold of in-patient care, aggressive supportive therapy, close materno-fetal monitoring and timely obstetric care are essential to manage the infection and to ensure a favourable pregnancy outcome.

\section{Funding: No funding sources Conflict of interest: None declared Ethical approval: Not required}

\section{REFERENCES}

1. Gehlot H, Yadav OP, Sharma S, Nagar GG, Yadav A, Gupta PP. A study of dengue fever in pregnancy and its maternal and fetal prognosis. Int J Reprod Contracept Obstet Gynecol. 2017;6:3414r7.

2. Kanakalatha D, Radha S, Nambisan B. Maternal and fetal outcome of dengue fever during pregnancy. Int J Reprod Contracept Obstet Gynecol. 2016;5(11):3959-64.

3. Pavanaganga A, Sailakshmi MP, Rekha BR, Nagarathnamma R. Dengue fever during pregnancy: maternal and fetal complications. J South Asian Fed Obstet Gynaecol. 2017;9(2):88-91.

4. Singh N, Sharma KA, Dadhwal V, Mittal S, Selvi AS. A successful management of dengue fever in pregnancy: report of two cases. Indian $\mathrm{J}$ Med Microbiol. 2008;26(4):377.

5. Machain-Williams C, Raga E, Baak-Baak CM, Kiem S, Blitvich BJ, Ramos C. Maternal, fetal, and neonatal outcomes in pregnant dengue patients in Mexico. BioMed Res Int. 2018;2018.

6. National Guidelines for Clinical Management of Dengue Fever- NVBDCP. Director General of Health Services, Ministry of Health and Family Welfare, Government of India; World Health Organisation, 2015. Available at: pbhealth.gov.in. Accessed on $05^{\text {th }}$ February 2020.

7. Dengue in Pregnancy: Management protocols FOGSI; 2014. Available at: https://www.fogsi.org/ wp-content/uploads/2015/11/dpmp.pdf. Accessed on $05^{\text {th }}$ February 2020.

Cite this article as: Singh T, Singh SM, Paprikar MM. Dengue in pregnancy, maternal and fetal outcome: a case series managed at a Zonal Hospital. Int J Reprod Contracept Obstet Gynecol 2020;9:2420-3. 